Rev. Hist., N²6, vol. 2, Julio-Diciembre 2019: 81 - 93

ISSN 0717-8832

\title{
Microhistoria de una familia italiana: el caso de los Viacava Castruccio en el puerto de Iquique, 1912-1954*
}

\author{
Micro-story of an italian family: the Viacava castruccio case in iquique harbor, \\ 1912-1954
}

\section{RESUMEN}

Marcos Calle Recabarren**

El presente artículo analiza en perspectiva microhistórica los hechos de la vida pública y privada de una familia italiana. En este caso los Viacava Castruccio, en sus orígenes, relaciones internas, devenir cotidiano, actividades económicas, y gestión patrimonial, alcanzado a través de los años como consecuencia del trabajo individual y familiar. Nuestro planteamiento, sugiere que los migrantes, luego de la partida de su lugar de origen, vivieron un tiempo de ajuste, adaptación y asimilación. En el puerto de Iquique, la mayoría de los italianos que llegaron solteros formaron familia y juntos con aquellos que vinieron con sus esposas e hijos, se integraron mayormente en la sociedad receptora.

Palabras claves: Inmigración, integración, italianos, familia Viacava

\section{ABSTRACT}

The present article analyses from a micro-story the facts of the public and private life of an italian family. In this case, the Viacava Castruccio Family, related to its origins, internal relationships, cotidian development, economical activities, and the management of patrimony. All this achieved across the years as consequence of individual and familiar work. Our approach suggests that the migrants, after leaving their original place, they lived a period of adjustment, adaptation and assimilation. In the lquique Harbor, most of the italians who arrived were single, formed a family, and came together with those who came with their wives and children. All of them integrated into the receptive society.

Keywords: Micro-story, italians, inmigration, integration, Viacava Castruccio family.

Recibido: mayo 2019

Aceptado: diciembre 2019

\footnotetext{
* Este artículo es un acápite de mi tesis doctoral Calle, M. 2017. Lejos del nido y en arenas extrañas: Inmigrantes italianos en la provincia de Tarapacá, 1860-1940, Tesis Doctoral en Historia de la Pontifica Universidad Católica de Chile.

** Doctor en Historia, Académico de la Universidad Católica de la Santísima Concepción. Email: mcalle@ucsc.cl.
} 


\section{Introducción}

En Italia se produjo uno de los movimientos migratorios más masivos acaecidos durante los siglos XIX y XX. Entre 1866 y 1976 salieron desde esa península cerca de 26.000 .000 de personas y de ellas más de la mitad, unos 14.000.000, lo hicieron antes de la Gran Guerra ${ }^{1}$. Entre 1860 y 1914, 3.500.000 millones de italianos abandonaron su tierra natal, y se dirigieron a Estados Unidos; otros 2.000.000 emigraron a Argentina y 1.000 .000 a Brasil. Si bien la mayoría de los italianos prefería Norteamérica y la costa Atlántica, el Perú alejado de los grandes centros de atracción de corrientes migratorias del siglo XIX, a contar de la década de 1860, acogió varios miles de italianos, con un promedio de 500 por año, salvo el periodo entre 1873 y 1875, cuando ingresaron 3.000, debido a un programa especial del gobierno peruano ${ }^{2}$. De igual modo, en Chile, en términos cuantitativos, el arribo de italianos no era significativo, pues por ejemplo, en 1865 llegaron 980 italianos; en 1875 1.922; en 1885 aumentaron a 4.114³.

Dentro del conjunto de europeos que llegaron a la provincia de Tarapacá, bajo soberanía peruana y después chilena, estaban los italianos, que en general fueron personas que no tenían el apoyo de su gobierno, por ende, debieron forjarse su propio destino por medio del trabajo independiente. Estos nuevos migrantes con el transcurso de los años vinieron a reforzar los sectores medios emergentes orientando sus actividades en sector servicios, prioritariamente al comercio, mediano y pequeño empresariado, profesiones liberales y técnicos ${ }^{4}$.

Para los migrantes italianos la principal vía de acceso era el puerto de Iquique, con sus playas, La Puntilla, El Morro y el casco urbano del centro, que ponían el sello característico a la ciudad. Además, este puerto era un espacio con permanentes flujos comerciales, e igualmente con desplazamientos de marinos, empleados, comerciantes, jornaleros, mineros y numerosos trabajadores que, por diversos motivos estaban ligados a las faenas portuarias y labores extractivas del salitre en la pampa de Tarapacá. Se trataba fundamentalmente de aventureros, buscadores de riqueza, jóvenes dispuestos a enfrentar desafíos y a lograr una posición que difícilmente podrían obtener en sus lugares de origen, conformando así una nueva sociedad con identidad cultural diferente del resto del país 5 .

Los estudios sobre migrantes no han sido temas de mucho interés en Chile, puesto que, hubo reducidas cantidades de inmigrantes que arribaron a nuestro país en comparación a otras

\footnotetext{
${ }^{1}$ Leonardo Mazzei. 1989. La inmigración italiana en la provincia de Concepción, 1890-1930. Tesis para optar al grado de Doctor en Historia en La Pontificia Universidad Católica de Chile, p. 18.

${ }^{2}$ Worral, Janet E. 1990. La inmigración italiana en el Perú, 1860-1914. Lima, pp. 3-5.

${ }^{3}$ Censos de la república de Chile.

${ }^{4}$ Calle, Marcos. 2017. “Lejos del nido y en arenas extrañas: Inmigrantes italianos en la provincia de Tarapacá, 1860-1940", tesis doctoral inédita de la Pontificia Universidad Católica de Chile, p. 7.

${ }^{5}$ Calle, Marcos. 2013. "Poblamiento e inmigración en Tarapacá" en Marcelo Jara y Felipe López (eds.), Migraciones. Una Mirada Interdisciplinaria, Concepción, p. 22.
} 
naciones. Investigaciones de nivel doctoral realizadas por investigadores extranjeros o chilenos en el extranjero, como Baldomero Estrada sobre los españoles en Valparaíso en la Universidad Complutense de Madrid $^{6}$ y algunos chilenos residentes como Leonardo Mazzei que hizo su tesis doctoral sobre los italianos en Concepción en la Pontificia Universidad Católica de Chile ${ }^{7}$. Sin duda, la investigación de Mazzei destaca la posición de los italianos en la estructura demográfica y el rol económico comercial dentro de los sectores medios emergentes, a causa de la capacidad de trabajo y ahorro.

Sobre la colectividad italiana en Chile, no existen muchos estudios. Hay una bibliografía tipo compendio y descriptiva, que entregan importante información durante las primeras décadas del siglo XX, referida a las principales actividades económicas; instituciones que fundaron y aportes de los peninsulares en Chile ${ }^{8}$.

En la década de 1990 surgieron investigaciones con renovadas metodologías de las ciencias sociales, provenientes de académicos de universidades chilenas. Una de ellas se publicó en 1994, correspondiente a la colección de monografías que patrocina la Pontificia Universidad Católica de Valparaíso, denominada "La presencia italiana en Chile" especialmente en zonas como Santiago, Valparaíso, Tarapacá, Concepción y Punta Arenas ${ }^{9}$. El primer trabajo de René Salinas sobre los italianos residentes en Santiago, desde una perspectiva demográfica estableció las características propias de los procesos migratorios europeos en Chile, y la integración social de italianos vía connubio, utilizando censos de población, fuentes parroquiales y civiles $^{10}$. Seguidamente sobre italianos en Valparaíso, Baldomero Estrada, enfatiza la importancia que tuvieron las redes de paisanaje para mantenerse en inversiones en industrias y comercio de nivel intermedio y bajo en el proceso productivo urbano ${ }^{11}$. El tercer

\footnotetext{
${ }^{6}$ Baldomero Estrada, 2012. Desarrollo Empresarial Urbano e Inmigración Europea: Españoles en Valparaíso, 18801940. Memoria para optar al grado de Doctor en Historia, Universidad Complutense de Madrid; Carl Solberg, 1970.Immigration and Nationalism. Argentina and Chile, 1890-1914, Institute of Latin American Studies, University of Austin Press,; George Young.1974. Germans in Chile: Immigrations and Colonization, 1849-1914, Center for Migrations Studies, New York; Jean Pierre Blancpain. 1974. Les Allemands au Chili, 1816-1945, Colonia, Böhlau Verlag; Moche Nes El.1999. La Inmigración y Colonización en Chile. Políticas de Colonización y Lealtades Etnicas (1880-1920). Tesis para optar al grado de doctor en Filosofía, Universidad Hebrea de Jerusalén.

${ }^{7}$ Mazzei, Leonardo. La inmigración italiana en la provincia de Concepción, 1890-1930. Tesis Doctoral en Historia de la Pontificia Universidad Católica de Chile.

${ }^{8}$ Blaya A, Joaquín. 1921. El progreso italiano en Chile, Resumen general de las actividades que ha desarrollado en Chile la colonia italiana, Santiago, Editorial Río de la Plata; Pellegrini Amadeo y Aprile Jorge Ciro.1926.El censo comercial e industrial de la colonia italiana en Chile. Resumen general de las actividades de la colonia, Editorial Río de la Plata, Santiago; Biaggio Luciano y Massone Paolo.1996. Presencia Italiana en Chile. Santiago Prezensa; GiulianiBalestrino; María Clotilde.2000., L'Italia fuori dall'Italia. Gli italiani in Cile. Génova, Bozzi Editore.

${ }^{9}$ Baldomero Estrada (ed.), Presencia Italiana en Chile. Valparaíso, 1993.

${ }^{10}$ René Salinas, "Perfil demográfico de la inmigración italiana a Chile" en B. Estrada (ed.), op. cit.

${ }^{11}$ B. Estrada, "Participación italiana en la industrialización de Chile. Orígenes y evolución hasta 1930” en B. Estrada (ed.), op. cit.
} 
trabajo de Julio Pinto, fundamental para la elaboración de historias regionales en forma panorámica realza por medio del estudio de casos de italianos, la participación permanente que sin duda era el espacio económico y social tarapaqueño: los salitreros, el mediano y pequeño comercio, incluyendo dentro de tal categoría las pequeñas industrias de bienes de consumo ${ }^{12}$. Otra monografía que nos adentra en la temática migratoria es de Mateo Martinic sobre italianos en Magallanes y su influencia económica y social en el devenir de un centro portuario dinámico como Punta Arenas ${ }^{13}$. A nuestro juicio estas monografías centradas fundamentalmente en el análisis regional, pueden ser consideradas una de las primeras tentativas colectivas, para entender la inmigración italiana en Chile desde un perfil unitario y documentado. Es decir, son estudios modelos por su carácter sociodemográfico, económico y cultural.

A partir de estos estudios sobre migrantes italianos, constatamos que la cadena migratoria es una herramienta eficaz para estudiar la migración, porque no lo concibe como un proceso de ruptura, sino como un proceso interactivo, que une lugar de origen y lugar de destino y explica el proceso de ajuste, adaptación e integración en la sociedad receptora. También, la cadena migratoria ya no era entendida como algo permanente y bipolar, sino que se postulaba como sistema diverso, donde interactuaban sus componentes entre sí. Tenemos la certeza que esta nueva manera de conceptualizar la cadena migratoria, produjo una aproximación a la red social, porque los posteriores estudios migratorios, enfatizaron las múltiples direcciones y relaciones, permitiendo estudiar de mejor modo los procesos microsociales que estaban dentro de las migraciones internacionales.

Los fenómenos migratorios son complejos y también incluyen aspectos demográficos, culturales, sociales, económicos, tanto en el país receptor, como en la nación de origen de la población emigrada. Si bien, la tendencia es analizarla como una cuestión macro-social, en verdad involucra la historia de millones de personas. Considerar esto, implica no atender solamente los factores económicos, sino tener una mirada microsocial que integre los aspectos antropológicos, sociológicos y demográficos. En ese sentido, diferenciamos dos conceptos muy parecidos: cadena migratoria y red social, en el caso del primer concepto siguiendo a los investigadores australianos de Camberra: John y Leatrice MacDonald, señalan que la migración en cadena, es el "movimiento en el que los futuros migrantes se enteraron de las oportunidades, son provistos de transporte y obtienen sus alojamientos y empleos iniciales, a través de relaciones sociales primarias con inmigrantes anteriores". La contraponen a la emigración organizada impersonalmente, la que definen como un movimiento basado en el

\footnotetext{
12 Julio Pinto 1993 “La presencia italiana en el ciclo salitrero: Tarapacá, 1860-1900” en B. Estrada (ed.), op. cit.

${ }^{13}$ Mateo Martinic 1993. "Presencia e inmigración italiana en Magallanes” en B. Estrada (ed.), op. cit.
} 
reclutamiento y la asistencia impersona $\left.\right|^{14}$. En nuestro análisis microsocial consideramos dos cuestiones planteadas en la definición citada: primero, información o conocimiento de oportunidades y segundo, asistencia o ayuda para emigrar y conseguir empleo. En ambos procesos se podrá entender quién emigra y quién no, cuándo y a dónde, y por qué, con mucha más precisión que apelando a correlaciones de variables macro-estructurales.

Además, estos autores distinguen básicamente una secuencia de tres tipos de cadenas migratorias para el periodo comprendido entre 1880 y 1914: la migración de varones a través de agentes laborales o padroni; la migración en serie de trabajadores merced a la ayuda de trabajadores aislados ya establecidos; y la migración con posterioridad de la familia, cuando la esposa e hijos se unían a sus maridos que habían partido primero en busca de trabajo ${ }^{15}$.

Franco Ramella propone el uso fuerte de la red social, donde los migrantes están integrados e interactuando con otros, para perseguir objetivos comunes y movilizar todos los recursos relacionales o relaciones personales que tienen a su disposición, con el fin de obtener información, elegir destino y crear oportunidades, para insertarse en el mercado laboral de la sociedad local. Las relaciones sociales, no dependen tanto de los atributos de los migrantes, más bien de los lazos de parentesco; de amistad; de vecindad ${ }^{16}$.

Esta nueva manera de observar al migrante dentro de una red, cambió la visión de la migración como una acción de desesperados a partir de situaciones trágicas, y se convierte en una elección de personas motivadas por crear estrategias de superación. En caso de la familia Viacava Castruccio, las redes sociales la hemos estudiado a partir de tres dimensiones operativas básicas: migrantes individuales; las relaciones de parentesco existente entre migrantes; y la pertenencia a una misma área de origen o vecindad espacial. Con la noción de migrante individual, hacemos referencia a los migrantes sin relaciones de parentesco directas y de vecindad espacial verificadas superficialmente en las fuentes. En las dimensiones b) y c), dos individuos que provienen del mismo pueblo o aldea o que tienen lazos de parentesco directo entre sí son considerados como formando parte de la misma red migratoria. Se trata, por tanto, de redes sociales pre-migratorias de carácter primario, esto es: suponen un conocimiento directo o de carácter interpersonal entre los migrantes o sus familias. Incluso un mismo individuo puede pertenecer simultáneamente a una red familiar, o de vecindad espacial. Por esta razón, nuestro análisis familiar, integra a los individuos como formando parte de un solo conjunto que incluye a migrantes italianos en redes, cualquiera sea la naturaleza de estas. Vale decir, las redes migratorias permiten identificar la naturaleza del proceso migratorio de los

\footnotetext{
${ }^{14}$ John. S. y Leatrice MacDonald.1964. "Chain Migration, Ethnic Neighbourhood Formation and Social Networks”, The Milbank Memorial Fund Quarterly, (New York), XLII, 1, 82-97.

15 John y Leatrice MacDonald, op. cit., 82-97.

16 Ramella, Franco.1995. "Por un uso fuerte del concepto de red en los estudios migratorios" en M. Bjerg y H. Otero (Eds.), Inmigración y redes sociales en la Argentina moderna, Tandil, CEMLA-IHES, pp?9, 10, 15, 21.
} 
italianos a Tarapacá. Además, corroboran la relevancia que tienen los orígenes regionales de los inmigrantes, para explicar plenamente sus características profesionales y culturales, los intereses, las aspiraciones tan sentidas, su capacidad organizativa y su cultura local.

Según Peter Burke, la microhistoria es una nueva forma de hacer historia, cuyo énfasis radica en la libertad de elección que tienen las personas comunes, sus estrategias, sus capacidades para aprovechar las oportunidades que ofrecen los sistemas sociales y políticos -encontrar espacios donde desarrollarse y/o subsistir $-{ }^{17}$. También Giovanni Levi define la microhistoria como una práctica historiográfica que reduce la escala de observación de forma variable y con independencia del objeto de estudio; la teoría, los conceptos y herramientas de las ciencias sociales refuerzan la descripción y análisis microhistórico; la cantidad y calidad de las informaciones son variables, por tanto, es necesario examinar pluralidad de formas de pensar que operan en la realidad particular; las acciones, conductas, roles, relaciones, estrategias y estructuras sociales derivan del análisis del objeto de estudio; el relato se elabora a través de una relación de hechos concretos que explican el funcionamiento de la sociedad, seguidamente se incorpora el aparato erudito - técnicas, procedimientos, conceptos, teorías, limitaciones, hipótesis, interpretaciones-, como parte intrínseca y explícita de la investigación; la contextualización sitúa formal y comparativamente un suceso, conducta o concepto. En síntesis, estas son las cuestiones y posiciones que caracterizan la microhistoria ${ }^{18}$.

Creemos que a través del enfoque microhistórico nos aproximamos al análisis de las redes sociales, en el cual los individuos son capaces de elegir, de pensar estrategias de sobrevivencia o de movilidad geográfica, social y económica. Además, la noción de redes sociales es la más adecuada, puesto que permite explicar el fenómeno de la migración como un proceso social dinámico caracterizado por una conjunción de relaciones permanentes e intensas, ya sea verticales $\mathrm{u}$ horizontales.

Relacionado con el enfoque y conceptualización anterior, planteamos como hipótesis, que el proceso de integración de la colectividad italiana en la provincia de Tarapacá se inició principalmente a partir de 1880 durante la época chilena, pues era interesante para quienes estaban dispuestos a integrarse como empresarios en distintos niveles, a causa del crecimiento de la economía regional cuyo pivote era la explotación del salitre. La llegada de los italianos, se produjo de forma individual, en forma espontánea, selectiva y minoritaria, en cambio otros arribaron siendo parte de redes sociales, con cierta seguridad y menor incertidumbre respecto del medio social que los acogía. Una vez radicados en la zona, algunos se vincularon con la explotación de salitre, aunque la mayoría se integraron como empresarios independientes en

\footnotetext{
17 Burke, Peter. 2003. “Obertura: La nueva historia, su pasado y su futuro" en Formas de Hacer Historia, 2a edición P. Burke (ed.), Madrid, pp. 31-32.

18 Levi, Giovanni. 2003. "Sobre microhistoria" en Formas de Hacer Historia, 2a edición, P. Burke (Ed.), Madrid, pp.122, 123, 127, 131, 133, 134.
} 
actividades complementarias como el pequeño y mediano comercio, según sus potencialidades y oportunidades que ofrecía la economía regional. En efecto, nuestro objetivo prioritario es reconstruir la trama familiar de los Viacava Castruccio, protagonistas de esta investigación no solo en la sociedad de destino de lquique, Pisagua y la Pampa, sino también, en la sociedad de origen identificada con el paese. De esta manera, logramos comprender la función que cumplieron las redes sociales, a través de vínculos parentales, amicales y de paisanaje en la experiencia migratoria que vivieron cientos de familias italianas.

\section{Origen Migratorio}

Los orígenes de la familia Viacava, comenzaron con Giovanni Battista Giacomo Viacava Merello, nacido el 25 de julio de 1885 en Rapallo, cuyos padres eran Agostino y Giulia ${ }^{19}$. Las condiciones económicas de la familia Viacava en el pueblo de San Michelle Pagano no eran tan favorables, lo que obligó a Giacomo siendo adolescente a trabajar como aprendiz junto a su padre, un experimentado pescador. Giacomo después de trabajar en la pesca se enteró sobre mejores oportunidades laborales en Iquique, a través de la familia conformada por Angelo Emanuele Castruccio y su esposa Ida Barbarini Boero ${ }^{20}$.

Giacomo Viacava, una vez arribado a Iquique a comienzos del siglo XX, ingresó como empleado en la tienda Boero y Cía., y después de años de arduo trabajo pudo ahorrar y retornar a su pueblo San Michelle Pagano, con el fin de encontrar una esposa. En Rapallo el 11 de octubre de 1922, Giacomo contrajo matrimonio con María Teresa Castruccio Barbarini ${ }^{21}$, nacida el 27 de abril de 1905 en Rapallo, cuyos padres eran Angelo e Ida ${ }^{22}$. Finalmente, los esposos Viacava Castruccio el mismo año de su boda decidieron radicarse en lquique con 38 años y 17 años, respectivamente ${ }^{23}$, de cuya unión nacieron sus hijos Italo, Rinaldo y Livia ${ }^{24}$.

\section{Trayectoria Laboral y Comercial}

Uno de los mecanismos utilizados por migrantes para lograr la independencia económica era ahorrar dinero e invertir en negocios asociándose con parientes o compatriotas. Así ocurrió con

19 Ufficio di Stato Civile; Estratto per riassunto dai Registri degli atti di nascita; atto ${ }^{\circ}{ }^{\circ}$ 197; parte 1 serie del comune di Rapallo, anno 1885.

${ }^{20}$ Angelo Castruccio e Ida Barbarini arribaron solteros a Iquique en 1891 y 1900, respectivamente; Registro de Nacionales Italianos inscritos en el Viceconsulado de Italia en Iquique, en adelante RNVII; Archivo del Registro Civil de Iquique, libro de Matrimonios, 05-02-1902, inscripción $n^{\circ} 28$. En adelante RCI, LM.

${ }^{21}$ Ufficio di Stato Civile; Estratto per riassunto dai Registri degli atti di matrimonio; atto $\mathrm{n}^{\circ} 87$; parte 1 serie, anno 1922.

22 Ufficio dello Stato Civile; Estratto per riassunto dai Registri degli atti di Nascita; iscrizione $n^{\circ}$ 94, parte 1; Serie del Comune di Rapallo anno 1905.

23 RNVII.

${ }^{24}$ Las informaciones sobre la vida familiar de los Viacava Castruccio, fueron extraídas de la entrevista a Livia Viacava (hija menor) realizada el 10-01-2015 en Iquique. 
los hermanos Giacomo y Luigi Viacava, que el 30 de abril de 1912 en Iquique formaron una sociedad comercial para girar en el rubro tienda en calle Tarapacá $n^{\circ} 195$. El capital era $\$ 30.000$ en mercaderías y dinero efectivo y la razón social era "Viacava Hnos.", cuya duración era cinco años y el uso de la razón social y administración del negocio estuvo a cargo de ambos socios ${ }^{25}$. Tiempo después abrieron sucursal en Tacna. Sin embargo, el 24 de abril de 1914, los hermanos Viacava disolvieron la sociedad comercial, quedando Giacomo con la sucursal de Tacna y Luis con la tienda de Iquique ${ }^{26}$.

Seguidamente, Giacomo Viacava el 12 de diciembre de 1917, se asoció con los comerciantes italianos José Boero, David Besaccia, Teodoro de Bernardis, Lorenzo Aste Merello - primo de Giacomo-, y Gerónimo Aste, para establecer un negocio de mercaderías nacionales e importadas, cuyo capital era \$709.949. Boero, Besaccia y De Bernardis, eran los únicos que podían utilizar la razón social "Boero y Cía.", y administrar el negocio durante tres años ${ }^{27}$. El cuatro de agosto de 1925, hubo reformas en la sociedad comercial, pues Viacava se incorporó como administrador, junto a Boero y De Bernardis. El capital de la sociedad alcanzó a \$915.309 y programaron la duración de la sociedad por tres años más ${ }^{28}$. Finalmente, esta sociedad comercial fue disuelta el 5 de agosto de 1932, quedando el activo y pasivo del negocio a cargo de Boero y el resto de los socios recibieron sus aportes y utilidades ${ }^{29}$.

Nuevamente se asociaron Viacava y Boero, junto a dos nuevos comerciantes italianos Mario Barbarini Boero ${ }^{30}$ y Renato Tassara Gianollo, el dos de agosto de 1933, formaron una sociedad comercial para la compraventa de mercaderías nacionales e importadas de tienda, mercería, repuestos y accesorios para automóviles -Fiat-, ubicada en Vivar $n^{\circ} 765$. Esta vez la administración y operaciones comerciales estarían a cargo de todos los socios indistintamente, en cambio la razón social "Boero y Cía.", solo podían utilizar Boero y Barbarini. El capital del negocio sumaba $\$ 562.883$, aportados por los socios en dinero efectivo, mercaderías, créditos por cobrar, útiles y enseres, y la duración de la sociedad sería cuatro años ${ }^{31}$.

El 28 de julio de 1937, los socios Viacava, Boero, Barbarini y Tassara, decidieron expandir la tienda, hacia rubros como paquetería, mercería, repuestos y accesorios para autos y camiones, cuya razón social era Boero y Cía., que podían utilizar Boero y Barbarini, mientras que Viacava y Tassara se ocuparían de las operaciones mercantiles por cuatro años. El capital del negocio

\footnotetext{
${ }^{25}$ Archivo Notarios de Iquique, Registro de Comercio, 1912, vol. 577, $n^{\circ} 45$, fs. 82-83, en adelante ANI, RC.

${ }^{26}$ ANI, RC, 1914, vol. 620, n 48, f. 31.

27 ANI, RC, 1917, vol. 4, n 99, fs. 135-136.

${ }^{28}$ ANI, RC, 1925, vol. 82, $n^{\circ} 104$, fs. 114-115.

${ }^{29}$ ANI, RC, vol. 124, $n^{\circ} 47$, fs. 118-119.

30 Barbarini era hermano de Ida, madre de María Teresa Castruccio Barbarini, esposa de Giacomo.

${ }^{31}$ ANI, RC, 1933 vol. $128, n^{\circ} 23$, fs. $46-48$.
} 
alcanzaba \$1.313.139, desglosado así: Boero \$864.764; Barbarini \$208.854; Viacava \$155.69 y Tassara $\$ 83.838^{32}$.

Los socios Boero, Barbarini, Viacava y Tassara, el 25 de mayo de 1953, esta vez decidieron dividir el negocio en dos secciones, la 1aㅡ: tienda, paquetería y mercería; la 2ạa: repuestos y accesorios de automóviles y camiones, las que estarían a cargo los tres primeros socios y el cuarto socio administraría y dirigiría la 2a sección. El capital de la tienda, paquetería y mercería ascendía a \$9.595.888, aportados como sigue: Boero \$5.447.128, Barbarini \$2.723.199; Viacava \$1.424.830, en mercaderías, útiles, enseres, valores por cobrar, dinero efectivo y depósitos en Caja Nacional de Ahorros; Banco Español-Chile; y Banco de Londres y América del Sud Ltda., de Santiago. Las secciones repuestos y accesorios de automóviles y camiones, tenía un capital que ascendía a \$2.216.717 en repuestos y accesorios de automóviles y camiones; y \$3.570.839 en valores por cobrar; Tassara aportó \$1.079.761, de su haber en la sociedad "Boero y Cía." 33 .

\section{Vida Familiar}

Consideramos relevante aproximarse a la vida cotidiana de una familia, puesto que sus miembros de forma privada reproducen repetidamente día a día, actividades; conocimientos; representaciones; creencias; afectos; relaciones sociales; usos; técnicas; instrumentos y objetos. Por tanto, en perspectiva micro social analizamos el ámbito privado de la familia Viacava Castruccio, primeramente en sentido material con la compra en 1945 de su vivienda en $\$ 45.000$ al contado a Eudocia Medina, viuda de Petersen. La vivienda estaba ubicada en calle Vivar $n^{\circ} 1507 /$ J. J. Pérez, cuya superficie medía 400 metros $^{34}$.

Sin duda la actuación de María Teresa Castruccio, fue más allá del tiempo que dedicaba y compartía en el hogar, como custodia de buenas costumbres de sus hijos y cuidado del esposo, puesto que tuvo un rol primordial en la economía doméstica, especialmente la alimentación, donde preparaba las tres comidas y congregaba a su esposo e hijos, tío Mario Barbarini y primo Eugenio Castruccio, en torno a una mesa común. A saber: el desayuno consistía en café de grano molido o leche caliente acompañado con pan, queso o jamón; la minuta de almuerzo semanal se basaba en la tradición culinaria italiana que solía ser spaghetti con salsa pomarola casera; rissotto con azafrán; menestrón; polenta; el postre era casi todos los días fruta fresca y ocasionalmente leche asada; sémola con leche; kuchen de nueces; dulces de zanahoria en bolitas y nueces rellenas. Los fines de semana en familia, Giacomo y María Teresa preparaban ravioles; panzotti; fetuccini; ñoquis; fideos al horno con huevo y pimienta negra; pastel de berenjenas; empanadas rellenas con arroz, zapallo y huevo; torta pascualina; tortillas de

\footnotetext{
${ }^{32}$ ANI, RC, 1937vol. 152, $n^{\circ} 36$, fs. 80-83.

${ }^{33}$ ANI, RC, 1953 vol. 241, $n^{\circ} 33$, fs. 82-86.

${ }^{34}$ ANI, RC, 1945 vol. 199, n 150, fs. 164-165.
} 
alcachofa; pejerrey relleno con pan molido con huevos y aliños; y focaccia. La albahaca indispensable en recetas italianas la cultivaban en una pequeña huerta ubicada en el patio de la casa. Los almuerzos familiares de fines de semana eran acompañados con vino tinto, donde solo hablaban idioma italiano ${ }^{35}$.

La familia Viacava festejaba el día de Italia; el 18 de septiembre; el 21 de mayo y la navidad con pastas, antipastos y dulces para los niños. No estaban ausente la carne al horno y pastel de carne molida. Otros eventos festivos donde participaba la familia Viacava eran la fiesta italiana Pentolaccia o caja rellena con dulces y premios sorpresa colgada en centro del salón, que era destrozada por un palo que tenía un invitado con ojos vendados. También, la fiesta de la primavera, cuya principal entretención era el baile y golosinas para niños y jóvenes ${ }^{36}$.

Según Livia Viacava, las comidas que representan una tradición local de origen italiano eran la polenta; menestrón; fogazzza, pizza; torta pascualina y tallarines, ravioles. También, los aromas de la cocina italiana eran la fragancia de la albahaca que emanaba del menestrón; el pesto; la pomarola o salsa de tomate con carne y sopa de verduras. Una parte de la tradición culinaria italiana que transmitió María Teresa a su hija Livia, eran las preparaciones de polenta con tuco (salsa de tomate y carne en trozos); el menestrón y la pomarola ${ }^{37}$.

Sin duda, la alimentación de la familia Viacava Castruccio dice relación con costumbres de un sector medio urbano de origen italiano con recetas variadas, cuyas comidas diarias tenían un orden regular de desayuno, almuerzo y cena.

\section{La descendencia}

Los cónyuges Giacomo y María Teresa tuvieron tres hijos, el primogénito Italo Humberto nació el 23 de septiembre de 1923 en Iquique. La educación primaria de Italo transcurrió primero en Iquique luego en Italia, y la secundaria en el Instituto Comercial de Iquique y posteriormente contabilidad en el Instituto Nacional de Comercio de Santiago INSUCO. Uno de los primeros trabajos que desempeñó Italo fue como contador en la tienda Boero y Cía., y también fue administrador en el negocio de sus suegros Sciaraffia dedicados a la agricultura en plantaciones de alfalfa y pulpería en el pueblo de Tarapacá. Italo se casó con Yolanda Sciaraffia el 22 de julio de 1949 en Iquique, de cuya unión nacieron: Italo (23-11-1950) ingeniero electrónico, María Angélica (19-06-1953) ingeniero civil industrial y constructor civil y Adelina (14-08-1955) contadora. En segundas nupcias, Italo contrajo matrimonio con Olga del Carmen Saavedra Muñoz el 23 de julio de 1968 en Concepción, de cuya unión nacieron en Concepción, Claudio (15 de agosto de 1967) mecánico automotriz, Paola Andrea (26-06-1970) matrona, Franco

\footnotetext{
${ }^{35}$ Entrevista a Livia Viacava. 10 de enero de 2017, Iquique.

${ }^{36}$ Ibid.

${ }^{37}$ Ibid
} 
Mauricio (10-02-1975) técnico eléctrico y Enzo Atilio (29-02-1977) técnico electrónico. Finalmente, Italo Humberto murió el 21 de agosto de 2016 en Santiago ${ }^{38}$.

Rinaldo nació el 29 de octubre de 1925 en Iquique, y sus estudios primarios los realizó en el Colegio Don Bosco de Iquique, y terminó $6^{\circ}$ humanidades en el Liceo de Hombres de lquique. Luego Rinaldo ingresó como cadete en la Escuela de Aviación, pero no terminó. Sin embargo, Rinaldo estudió odontología en la Universidad de Chile en Santiago. La trayectoria laboral de Rinaldo se inició como odontólogo en la Fuerza Aérea, base El Bosque, donde se jubiló con el grado de Comandante de Grupo en 1977. Paralelamente, Rinaldo tuvo su consulta particular en calle Catedral/Puente, pleno centro de Santiago. Rinaldo se casó con Eliana Cánepa Canessa el 12 de diciembre de 1954, hija de Domingo Cánepa Oneto y Gigina Canessa Solimano. Del matrimonio de Rinaldo con Eliana nacieron en Santiago: Carmen Gloria (22-10-1955) comerciante, Silvana Eliana (23-11-1956) ingeniero de ejecución en diseño industrial y Aldo (0902-1959) ingeniero agrónomo ${ }^{39}$.

Livia Anna, nació el 26 de julio de 1945 en Iquique. Los estudios primarios y humanidades de Livia los realizó en el Colegio María Auxiliadora, egresando en 1962. Una situación que afectó la continuidad de los estudios de Livia, fue una parálisis que padeció su padre Giacomo y la posterior enfermedad renal de su madre María Teresa. En consecuencia, Livia tuvo que reemplazar a sus padres durante dos años como dependiente en la tienda de Boero y Cía. A propósito del término de la sociedad comercial Boero y Cía., en 1964, Livia ingresó un año después a estudiar para profesora primaria en la Escuela Normal de Iquique. Al fallecer sus progenitores ese mismo año, no pudo continuar sus estudios. Sin embargo, Livia con el apoyo de su hermano Rinaldo, terminó su carrera en la Escuela Normal Brígida Walter de Santiago. Al egresar en 1966, Livia trabajó como profesora en escuelas primarias de Santiago e Iquique ${ }^{40}$.

Paralelamente a sus estudios, Livia conoció en un malón a un joven llamado Pedro Vargas Palape, oriundo de Pica, hijo de Ernesto y Lucila. Aquella amistad juvenil se mantuvo por varios años y hasta contraer matrimonio el 17 de septiembre de 1967. Luego, los esposos Vargas Viacava decidieron radicarse en Santiago, donde Livia trabajó en la Escuela Básica $n^{\circ} 307$ de Conchalí y Pedro se desempeñó como empleado en una empresa Constructora Giacconi y Cía., y posteriormente en la Cooperativa de Empleados Particulares. De la unión Vargas Viacava, nacieron en Santiago: Patricia Marisol (06-06-1968), administradora de propiedades; Pablo Andrés (29-06-1969), Licenciado en filosofía y psicólogo con magister en recursos humanos y

\footnotetext{
${ }^{38}$ Entrevista a Livia Viacava. 10 de enero de 2017, Iquique.

${ }^{39}$ Ibid.

${ }^{40} \mathrm{Ibid}$.
} 
Gabriel (12-08-1970), ingeniero informático. Actualmente Livia tiene 72 años de edad, se encuentra jubilada y es rentista de propiedades ${ }^{41}$.

Podemos afirmar que los tres hijos de Giacomo y María Teresa recibieron una educación formal y pudieron - no exentas de dificultades-, desarrollar actividades profesionales en ámbitos públicos y privados. En cuanto a elección de cónyuges los hermano Viacava Castruccio, no tuvieron pauta única al momento de casarse, puesto que, Italo en su primer matrimonio lo hizo con dama descendiente de italianos, en cambio, su segundo matrimonio fue exogámico, pues casó con chilena. Rinaldo tuvo similar comportamiento que su hermano, en el caso del primer matrimonio. En último término, Livia contrajo nupcias con un joven chileno, por tanto, fue exogámica.

Finalmente, los nietos todos chilenos recibieron educación universitaria, ya sea profesional y técnica y se encuentran muy integrados en la sociedad chilena.

\section{Patrimonio Familiar}

La enumeración de bienes inmuebles y muebles, se relaciona con prácticas que cambian con el transcurso del tiempo, ya que, por una parte los objetos son bienes privados de uso personal y son traspasados a familiares o amistades, y por otra, son mercancías con valor de uso, pero que va más allá de los afectos y se miden en términos monetarios. En una ciudad puerto como lquique, para los italianos y sus familias era fundamental obtener un inmueble donde vivir o recursos económicos para alimentación y vestuario, especialmente si estaban integrados en una economía de mercado. Así lo demostró Angelo Castruccio, quien falleció en Italia el 17 de marzo de 1946, cuyos bienes eran para sus hijos María Teresa y Francesco, consistentes en dos propiedades en lquique, avaluadas en $\$ 115.000^{42}$. Seguidamente el 24 de febrero de 1954, murió en Italia la viuda Ida Barbarini, quien dejó como herencia a sus dos hijos: una propiedad en Bolívar/A. Pinto; 360 acciones de \$40 c/u en La Chilena Consolidada; 242 acciones de \$20 c/u en la Compañía de Cervecerías Unidas; 200 acciones de $\$ 30$ c/u de "Italia Seguros" y 91 acciones de $\$ 1$ en el Banco Italiano ${ }^{43}$.

No menos importantes eran los bienes dejados por Giacomo Viacava, a causa de su fallecimiento con 79 años de edad en Iquique el 27 de enero de $1965^{44}$ y su esposa María Teresa Castruccio, fallecida con 60 años de edad el 31 de diciembre del mismo año ${ }^{45}$. Los bienes eran

\footnotetext{
${ }^{41}$ Ibid.

42 Archivo Notarios de Iquique, Registro de Bienes Raíces, 1948 vol. 214, n 499-500, fs. 495-497. En adelante ANI, RBR.

${ }^{43}$ ANI, RBR, 1962 vol. 303, n 442, fs. 448-450.

${ }^{44}$ Archivo del Registro Civil de Iquique, Libro de Defunción, 28 de enero de 1965, inscripción n 17 . En adelante ARCI, LD.

${ }^{45} \mathrm{ARCI}, \mathrm{LD}, 02$ de enero de 1966, inscripción $n^{\circ} 2$.
} 
una propiedad ubicada en O. Labbé $n^{\circ} 1086$ de 220 metros cuadrados; una propiedad ubicada en Bolívar/A. Pinto de 81 metros cuadrados. Además, 13.761 Escudos en el Banco de Chile; 4.000 Escudos en la firma Rossi\&Sfrasani; 2.699 acciones en la Sociedad Carozzi; 1.735 acciones en Celulosas Cholguán S.A.; 360 acciones en La Chilena Consolidada; 242 acciones en Compañía Cervecerías Unidas; 91 acciones en Banco Italiano; 200 acciones en La Italia Seguros; 199 acciones en "Ovolín" Fábrica de Alimentos Concentrados S.A., y un juego de living, comedor, dormitorio y vajilla ${ }^{46}$.

De las herencias dejadas por los progenitores Castruccio Barbarini y Viacava Castruccio, advertimos una intensa vida económica urbana, donde mayormente los bienes inmuebles sitio y casa-; los depósitos en dinero a interés; las acciones nominales y en dinero, adquirieron valor comercial y representaron el nivel económico alcanzado. De menor cuantía, muebles comedor, living, dormitorio, menaje-, en términos de significaciones, pueden considerarse "mercancías culturales" que representaban el prestigio social alcanzado. Incluso, la vajilla, la loza, los utensilios y objetos de cocina, son expresión visible de un estilo de vida, donde observamos el modo en el cual los recursos económicos fueron consumidos o disfrutados.

\section{Conclusión}

Esta historia familiar reafirma la importancia que tiene la microhistoria que, en los últimas cuatro décadas ha marcado las investigaciones que han evolucionado desde historias generales y oficiales, en el cual lo privado y cotidiano - común y corriente-, ha sido postergado por historias heroicas o al "pie de los monumentos". Esta situación nos permite proponer que la interpretación de conjunto mayormente puede surgir del análisis de las partes que estructuran el fenómeno. Por consiguiente, esta investigación constituye un avance para estudiar los procesos migratorios de los italianos en la región de Tarapacá, a través de la historia de la familia.

Como un estudio de caso, la experiencia migratoria de los esposos Viacava Castruccio, nos brinda la posibilidad de reflexionar acerca de una familia de italianos que abandonaron su natal Rapallo, cruzando mares y continentes para llegar al lejano puerto de lquique en búsqueda de un mejor porvenir. Con ellos vino su historia y sus proyectos personales, que fueron favorecidos por el acceso a informaciones divulgadas por paisanos o parientes de un mismo pueblo 0 ciudad. En este caso Giacomo y la familia Castruccio Barbarini eran de Rapallo, y comunicaron las oportunidades que ofrecía el puerto de lquique. Posteriormente, Giacomo una vez consolidado económicamente, retornó a Italia y se casó con la hija de ellos.

Las actividades económicas conjuntas de las familias Castruccio Barbarini y Viacava Castruccio, son interesantes de constatar, porque expandieron en redes económicas sus

${ }^{46}$ ANI, RBR, 1966 vol. 318, n 413, 415, fs. 350-352. 
inversiones en diferentes negocios. De igual modo, la caracterización de una red familiar, sus estrategias de cambio y roles que desempeñó cada miembro de la familia, para mantener el poder económico, demuestran que en la forma se puede ser comerciante, rentista o profesional, con mentalidad centrada en el ascenso social aferrada a los bienes materiales.

Desde esta perspectiva, planteamos la idea de complementariedad de roles económicos y familiares de los esposos Viacava Castruccio en un contexto de desigualdad en las relaciones de poder existentes al interior del entorno familiar marcado por el patriarcado urbano. Finalmente, la descendencia de la familia Viacava, se fortalecía con alianzas matrimoniales, no solamente con hijos e hijas de familias italianas que lograron consolidarse económicamente y tenían prestigio dentro de la sociedad en la cual estaban insertos, sino que también con miembros de la sociedad local, que avalaba un proceso de integración hasta la asimilación.

\section{Fuentes y Bibliografía}

Registro de Nacionales Italianos inscritos en el Viceconsulado de Italia en Iquique.

Registro Civil de Iquique:

- Libro de Matrimonios, 05-02-1902, inscripción nº 28.

- Libro de Defunción, 28 de enero de 1965, inscripción n 17; 02 de enero de 1966, inscripción nº 2.

Registro Civil de Italia:

- Ufficio di Stato Civile; Estratto per riassunto dai Registri degli atti di nascita; atto $n^{\circ}$ 197; parte 1 serie del comune di Rapallo, anno 1885.

- Ufficio di Stato Civile; Estratto per riassunto dai Registri degli atti di matrimonio; atto n ${ }^{\circ} 87$; parte 1 serie, anno 1922.

- Ufficio dello Stato Civile; Estratto per riassunto dai Registri degli atti di Nascita; iscrizione ${ }^{\circ} 94$, parte 1; Serie del Comune di Rapallo anno 1905.

Archivo Notarios de lquique:

- Registro de Comercio: 1912, vol. 577, $n^{\circ} 45,1914$, vol. 620, n 48; 1917, vol. 4, $n^{\circ} 99 ; 1925$, vol. 82, $n^{\circ}$ 104; 1932, vol. 124, n 47; 1933, vol. 128, n²3; 1937, vol. 152, nº 36; 1953 vol. 241, n 33; 1945 vol. $199, n^{\circ} 150$.

- Registro de Bienes Raíces, 1948 vol. 214, n 499-500; 1962 vol. 303, n 442; 1966 vol. 318, nº 413, 415.

- Entrevista a Livia Viacava realizada el 10-01-2015 en Iquique.

- Censos de la República de Chile.

\section{Bibliografía}

Burke, P. 2003. "Obertura: La nueva historia, su pasado y su futuro", en P. Burke (ed.), Formas de Hacer Historia, 2a edición, Madrid, Editorial Alianza Ensayo.

Calle, M. 2017. Lejos del nido y en arenas extrañas: Inmigrantes italianos en la provincia de Tarapacá, 1860-1940, Santiago, Pontifica Universidad Católica de Chile, Tesis para optar al grado de Doctor en Historia. 
Calle, M. 2013. "Poblamiento e inmigración en Tarapacá", en Jara, M. y López, F. (eds.), Migraciones. Una Mirada Interdisciplinaria, Concepción, El Sur Impresores.

Estrada, B. 2012. Desarrollo Empresarial Urbano e Inmigración Europea: Españoles en Valparaíso, 18801940, Madrid, Universidad Complutense de Madrid, Memoria para optar al grado de Doctor en Historia.

Estrada, B. (ed.). 1993. Presencia Italiana en Chile, Valparaíso, Instituto de Historia, Ediciones Universitarias de Valparaíso.

Estrada, B., "Participación italiana en la industrialización de Chile. Orígenes y evolución hasta 1930”, en

Estrada, B. (ed.). 1993. Presencia Italiana en Chile, Valparaíso, Instituto de Historia, Ediciones Universitarias de Valparaíso, pp. 89-124.

Martinic, M. "Presencia e inmigración italiana en Magallanes", Estrada, B. (ed.). 1993. Presencia Italiana en Chile, Valparaíso, Instituto de Historia, Ediciones Universitarias de Valparaíso, pp. 177-189.

Levi, G. 2003. "Sobre microhistoria”, en P. Burke (ed.), Formas de Hacer Historia, 2ª edición, Madrid, Editorial Alianza Ensayo, pp. 119-143.

MacDonald, J. S. y MacDonald, L. 1964. "Chain Migration, Ethnic Neighbourhood Formation and Social Networks", en The Milbank Memorial Fund Quarterly, XLII, 1, New York, pp. 82-97.

Mazzei, L. 1989. La inmigración italiana en la provincia de Concepción, 1890-1930, Santiago, Pontificia Universidad Católica de Chile, Tesis para optar al grado de Doctor en Historia.

Pinto, J. 1993. “La presencia italiana en el ciclo salitrero: Tarapacá, 1860-1900”, Estrada, B. (ed.). 1993. Presencia Italiana en Chile, Valparaíso, Instituto de Historia, Ediciones Universitarias de Valparaíso, pp. 61-88.

Ramella, F. 1995. "Por un uso fuerte del concepto de red en los estudios migratorios", en Bjerg M. y Otero H. (Eds.), Inmigración y redes sociales en la Argentina moderna, Tandil, CEMLA-IHES.

Salinas, R. 1993. "Perfil demográfico de la inmigración italiana a Chile”, Estrada, B. (ed.). 1993. Presencia Italiana en Chile, Valparaíso, Instituto de Historia, Ediciones Universitarias de Valparaíso, pp. 11-24. Worral, J. 1990. La inmigración italiana en el Perú, 1860-1914. Lima, Editorial Ausonia. 